\title{
Do the Cardiac Glands Exist?
}

\section{Humans}

\author{
Masatake IMAI, Taizo SHIBATA, Keiichi MORIGUCHI and Koshi YAMAMOTO \\ Department of Anatomy, Kanazawa Medical University, \\ Uchinada-machi, Kahoku-gun, Ishikawa 920-02, Japan
}

-Received for Publication, March 16, 1988-

Key words: Cardiac glands, esophageal cardiac glands, man, carbohydrate histochemistry.

Summary: We performed histological and histochemical investigations on the so-called cardiac glands and esophageal cardiac glands in man.

1. The upper and lower esophageal cardiac glands are compound tubular glands.

2. The so-called cardiac glands are composed of the compound tubular glands and simple or simple branched tubular glands.

3. A few parietal cells are found in the cardiac, upper and lower esophageal cardiac glands.

4. Pepsinogen granules can be found in the basal, body and neck portions of the simple or simple branched tubular glands in the cardiac region, in the terminal portions and ducts of the compound tubular glands in the same region and in the same prrtions of the upper and lower esophageal cardiac glands.

5. The cardiac glands and esophageal cardiac glands contain neutral, weak and strong acid mucopolysaccharides, sialomucin and neutral mucous of types II and III.

6. The fundic glands also possess the above-mentioned items 3-5. The authors believe that the fundic, cardiac and esophageal cardiac glands are the same kind of gland.

7. The authors presume that the esophageal cardiac glands and the compound tubular type of the so-called cardiac glands are an aggregate of the fundic glands. Namely, the terminal portions and ducts of the same glands correspond to the fundic glands.

8. The authors consider the compound tubular structure of the esophageal cardiac glands to be more advantageous than the scattering simple tubular glands to the mechanical injury which is produced by the passing of food.

9. The epithelium in the excretory ducts of the esophageal cardiac glands and compound tubular type of the so-called cardiac glands reacted strongly to PAS. This characteristic is common to that of the gastric pits. The epithelium in the same ducts of the esophageal glands was PAS negative.

10. Some scholars presume that the upper and lower esophageal cardiac glands are the partially transported cardiac glands in the esophagus and another scholar considers that the lower esophageal cardiac glands are the ectopic gastric mucous membrane in the esophagus. However, the authors deny these opinions and maintain that the cardiac glands of the compound tubular type are the extended portions of the lower esophageal cardiac glands. The authors presume that the esophageal cardiac glands are normal structure in the esophagus and embryologically develop from the cranial side to the caudal side. Incidentally, several esophageal glands occasionally enter into the cardiac region.

11. Based on the percentages of the upper esophageal cardiac glands in the fetus and adult, the authors presume that the same glands have a rudimentary tendency.

12. The authors believe that the simple or simple branched tubular glands in the cardiac 
region are undifferentiated fundic glands because the basal portions of the same glands still contain a PAS positive substance in large quantity.

13. The authors deny the presence of the cardiac glands which are acknowledged by other scholars and propose the terms of upper and lower esophageal fundic glands instead of upper and lower esophageal cardiac glands.

14. According to the studies of the authors, the Japanese macaque, crab-eating monkey, dog, cat, rabbit, cow, horse, swine, rat and mouse have no gland which correspond to the esophageal cardiac glands or compound tubular glands in the cardiac region (the so-called cardiac glands). Therefore, the authors believe the existence of the above-mentioned glands are characteristic only in man.

The glands in the cardiac region which are distributed in the immediate vicinity of the esophageal orifice are named the cardiac glands and those in the lamina propria in the upper and lower parts of the esophagus are designated the upper and lower esophageal cardiac glands. The above-mentioned glands in the stomach and esophagus are regarded as the same kind. Moreover, some scholars concluded that those glands secrete mucoid and others consider them to be mucous glands.

The authors performed detailed investigations on the same glands and demonstrated these glands to be nothing but an aggregate of the fundic (gastric) glands.

\section{Materials and Methods}

Sixteen adults ( 8 males, 7 females, 1 of unknown sex) were used for the investigations on the cardiac glands and lower esophageal cardiac glands. Moreover, seventeen adults ( 11 males, 6 females) were used for studies of the upper esophageal cardiac glands and seven adults ( 4 males, 3 females) for the fundic glands. All materials were obtained from dead bodies. These bodies were stored in 50-60\% ethyl alcohol after an intravenous injection of $4 \ell 10 \%$ formalin and injection of $1 \ell$ of the same solution into the abdominal cavity. The abovementioned embalment was performed before or eighteen hours after death. Incidentally, the same dead bodies were stored for the
Table 1. Staining technique.

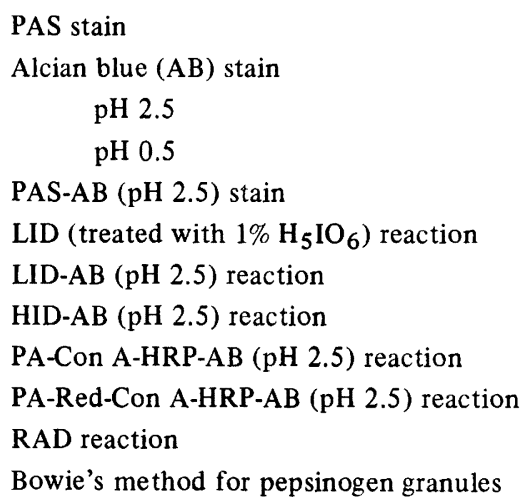

dissecting exercise by the students.

The tissues were embedded in paraffin and cut into sections of about $6 \mu$ in thickness. The sections were stained by the techniques shown in Table 1.

\section{Observations}

The materials used in the investigations were not fresh, however, the authors were able to obtain the data to study the characteristics of the glands in question.

I. The upper esophageal cardiac glands (Fig. 1).

Three out of seventeen specimens contained a small number of the same glands. They were relatively small compound tubular glands and their branching was 
uncomplicated. Each of them opened into the esophageal cavity with one excretory duct. Even when the same duct penetrated through the esophageal stratified squamous epithelium, the epithelium of the duct was simple columnar and reacted strongly to PAS and $\mathrm{AB}$ (pH 2.5) (Figs. 5, 6). A few parietal cells were found in the same glands (Fig. 2). Incidentally, when the excretory duct of the esophageal glands passed through the esophageal epithelium, the simple cuboidal epithelium in the same duct changed into stratified squamous epithelium (Fig. 3). Moreover, the epithelium in the excretory duct of the esophageal glands was PAS and $\mathrm{AB}(\mathrm{pH} 2.5)$ negative.

The histochemical reactions of the upper esophageal cardiac glands were as follows.

1. PAS stain: The glandular cells and the epithelium of the excretory duct reacted strongly to PAS.

2. $\mathrm{AB}(\mathrm{pH} 2.5)$ stain: The glandular cells reacted weakly or moderately to $\mathrm{AB}(\mathrm{pH}$ 2.5 ). Sometimes negatively reacted portions were found.

3. AB ( $\mathrm{pH}$ 0.5) stain: The glands generally reacted negatively to $\mathrm{AB}(\mathrm{pH} 0.5)$. However, weakly reacting portions were occasionally found.

4. PAS-AB ( $\mathrm{pH} 2.5$ ) stain: Some portions of the glands stained light violet and the others were dark violet.

5. LID (treated with $1 \% \mathrm{H}_{5} \mathrm{IO}_{6}$ ) reaction: The reaction color was light or dark gray.

6. LID-AB ( $\mathrm{pH} \mathrm{2.5)} \mathrm{reaction:} \mathrm{The} \mathrm{glands}$ reacted negatively to $\mathrm{LID}$, however, the ducts reacted moderately or strongly to $\mathrm{AB}$ (pH 2.5) and the reaction color of the terminal portion of the glands was light blue or colorless.

7. HID-AB ( $\mathrm{pH} 2.5$ ) reaction: The glands reacted negatively to the same technique.

8. PA-ConA-HRP-AB ( $\mathrm{pH} 2.5$ ) reaction: The reaction color in the terminal portion of the glands was dark brown. Half of a gland reacted moderately to $\mathrm{AB}(\mathrm{pH} 2.5)$ and the other half reacted weekly or negatively to the same $\mathrm{AB}$. The ducts generally reacted negatively to this method, however, small portions of brown or light blue were observed in a gland.

9. PA-Red-ConA-HRP-AB ( $\mathrm{pH} 2.5$ ) reaction: The reaction color in the whole portion of a gland was dark blue. In another case, half of a gland was dark blue while the other half was colorless. Moreover, in some cases, brown and blue reaction colors were observed in the terminal portion of a gland. The color of the ducts was light or dark blue.

10. PAD reaction: The reaction color of the glands was light brown.

11. Bowie's method for pepsinogen granules: Many pepsinogen granules were found in the glandular cells (Fig. 4). Parietal cells were red with this technique.

\section{The lower esophageal cardiac glands}

All the materials (15 individuals) used in this study contained the same glands in a large or occasionally small number (Figs. 5, 6). They were large compound tubular glands and their branching was complicated. The glandular terminals were generally tubules, however, sometimes they were large tubes. The glandular cells in the terminal were cuboidal and were arranged in a simple layer. When the tubes were large, the cells in these portions were columnar. The abovementioned tubules drained into a large tube and the same tube changed into the excretory duct. The same duct passed through the esophageal stratified squamous epithelium and opened into the esophageal cavity. The simple columnar epithelium of the excretory duct was still simple in the esophageal epithelium and reacted strongly to PAS and $\mathrm{AB}$ (pH 2.5) (Figs. 5, 6). A few parietal cells were found here and there in the glands (Figs. 7, 8).

The histochemical reactions of the lower 
esopageal cardiac glands were as follows.

1. PAS stain: Most glandular cells and epithelium of the ducts reacted strongly to PAS, however, some glands reacted weakly or negatively to the same stain (Fig. 5).

2. $\mathrm{AB}(\mathrm{pH}$ 2.5): The small terminal portions generally reacted weakly or negatively to $\mathrm{AB}(\mathrm{pH} 2.5)$ while the ducts reacted weakly or moderately to the same technique (Fig. 6).

3. $\mathrm{AB}(\mathrm{pH} 0.5)$ stain: The same glands reacted weakly or moderately to $\mathrm{AB}(\mathrm{pH}$ 0.5 ). However, some portions of the glands were unstainable with this stain (Fig. 9).

4. PAS-AB ( $\mathrm{pH} 2.5)$ stain: Some portions of the glands reacted strongly to PAS and the others stained dark blue or violet.

5. LID (treated with $1 \% \mathrm{H}_{5} \mathrm{IO}_{6}$ ) reaction: The reacting color of the glands was gray violet.

6. LID-AB ( $\mathrm{pH} \mathrm{2.5)} \mathrm{reaction:} \mathrm{The} \mathrm{glands}$ reacted negatively or weakly to $\mathrm{AB}(\mathrm{pH} 2.5)$ while a reaction color to LID was not observed.

7. HID-AB ( $\mathrm{pH} 2.5)$ reaction: The glands reacted weakly to $\mathrm{AB}(\mathrm{pH} 2.5)$, however, a reaction color to HID was not observed.

8. PA-ConA-HRP-AB ( $\mathrm{pH} \mathrm{2.5)} \mathrm{reaction:}$ The glands presented as yellowish brown.

9. PA-Red-ConA-HRP-AB (2.5) reaction: The glands presented as dark brown.

10. PAD reaction: The glands presented as light yellowish brown.

11. Bowie's method for pepsinogen granules: Except for the epithelium of the excretory duct, the cells of the terminal portions and ducts of the glands contained many pepsinogen granules (Figs. 10-13).

\section{The cardiac glands}

The glands which are distributed in the cardiac region are regarded as the cardiac glands. However, the structure of the same glands was not simple and contained such variation. Namely, type I were compound tubular glands which were similar to the esophageal cardiac glands. The same glands distributed in the lower end of the esophagus were mostly stretched over both the esophageal and cardiac regions (Figs. 15, $18,22,23)$. The first gland of type I generally adheres closely to the ostium cardiacum (Fig. 14). The type I glands neighboring the same ostium closely contacted each other, however, narrow connective tissue exists between both glands (Fig. 20). The same glands in the region apart from the ostium cardiacum were scattered (Figs. 16, 17). The spaces between the separated compound tubular glands were filled with simple or simple branched tubular glands (type II, Figs. 16, 17). The branching of the same glands became simple on the fundic side and finally these glands took the form of the fundic glands. The simple or simple branched tubular glands were always found in the cardia, howevever, the compound tubular glands were unrecognizable several times.

The cells of the terminal portions in the compound and simple tubular glands were generally cuboidal and were arranged in a simple layer. Accordingly, the terminal portions were tubules. The cells in the ducts and the excretory ducts of the glands were columnar and were arranged in a simple layer. However, sometimes the cells in the terminal portions of the compound tubular glands were columnar and the tubes were very large.

Incidentally, the ducts in the compound tubular gland are the portions between the terminal portions and excretory duct. The body in the simple branched tubular gland is the portion between the terminal portion and excretory duct. The excretory duct in the same gland corresponds to the gastric pit. A few parietal cells were distributed here and there in both cardiac glands (Fig. 21).

The histochemical reactions of the cardiac glands were as follows:

A. The compound tubular glands 
1. PAS stain: Some terminal portions were negatively, weakly or moderately stained with PAS while the others reacted strongly. The same reaction in the ducts was strong. (Figs. 15, 18).

2. $\mathrm{AB}(\mathrm{pH} 2.5)$ stain: Most of the terminal portions reacted negatively to $\mathrm{AB}$ (pH 2.5), however, some glandular cells reacted weakly or strongly to the same stain. The greater part of the ducts reacted moderately or strongly to the same technique. Some ducts showed a weak or negative reaction to $\mathrm{AB}(\mathrm{pH} 2.5)$ (Figs. 20, 22)

3. $\mathrm{AB}(\mathrm{pH}$ 0.5) stain: Most of the terminal portions reacted negatively to $A B$ (pH 0.5), however, some portions showed weak, moderate or strong reaction to the same stain. Some ducts reacted moderately or strongly to $\mathrm{AB}$ ( $\mathrm{pH} 0.5$ ) while other ducts reacted negatively to the same technique (Fig. 23).

4. PAS-AB ( $\mathrm{pH}$ 2.5) stain: Various reaction colors were produced. Namely, whole portions of some glands were dark violet and others reacted strongly to PAS. Violet and PAS positive portions were mixed throughout a gland. The color of the ducts was generally violet or dark blue.

5. LID (treated with $1 \% \mathrm{H}_{5} \mathrm{IO}_{6}$ ) reaction: The color of the glands was light gray violet.

6. LID-AB ( $\mathrm{pH} 2.5)$ reaction: The terminal portions of the glands reacted negatively or weakly to $\mathrm{AB}(\mathrm{pH} 2.5)$ and some ducts weakly or moderately to the same $\mathrm{AB}$. The reaction to $\mathrm{LID}$ was negative.

7. HID-AB ( $\mathrm{pH} 2.5)$ reaction: Most of the glands reacted negatively to $\mathrm{AB}(\mathrm{pH} 2.5)$ and some glands partially reacted moderately or strongly to the same $\mathrm{AB}$. The reaction to HID was negative.

8. PA-ConA-HRP-AB ( $\mathrm{pH} \mathrm{2.5)} \mathrm{reaction:}$ The reaction color was yellowish brown.

9. PA-Red-ConA-HRP-AB (pH 2.5) reaction: The whole portion of the glands generally presented yellowish brown while in some cases, partially colorless terminal portions were found. The ducts in this gland reacted weakly or strongly to $\mathrm{AB}(\mathrm{pH} 2.5)$.

10. PAD reaction: The reaction color of the terminal portions was light brown or yellowish brown and the ducts reacted negatively to this technique.

11. Bowie's method for pepsinogen granules: A large number of pepsinogen granules were recognized in the terminal portions and ducts of the glands (Fig. 24).

B. The simple or simple branched tubular glands

1. PAS stain: The epithelium of the excretory ducts and the glandular cells in the neck and body portions reacted strongly to PAS while the cells in the basal portions ranged from weakly to moderately reactive to the same stain (Figs. 16, 17).

2. $\mathrm{AB}(\mathrm{pH} 2.5)$ stain: The epithelium in the excretory ducts reacted weakly or moderately to $\mathrm{AB}$ ( $\mathrm{pH} 2.5$ ) and the basal and body portions were generally negative, however, the same portions rarely reacted weakly to this technique.

3. $\mathrm{AB}(\mathrm{pH} \mathrm{0.5)}$ stain: Most glands reacted

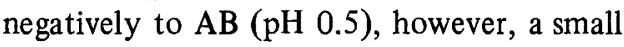
number of weakly reactive bodies and excretory ducts were observed. Few basal portions reacted weakly to this stain.

4. PAS-AB ( $\mathrm{pH} 2.5)$ stain: The reacted color of the glands varied from red, violet, dark blue and so forth.

5. LID (terated with $1 \% \mathrm{H}_{5} \mathrm{IO}_{6}$ ) reaction: The reaction color was light gray.

6. LID-AB ( $\mathrm{pH} 2.5)$ reaction: The reaction color was gray. The epithelium of the excretory ducts reacted weakly to $\mathrm{AB}(\mathrm{pH}$ 2.5).

7. HID-AB ( $\mathrm{pH}$ 2.5) reaction: The reaction to this technique was negative.

8. PA-ConA-HRP-AB ( $\mathrm{pH} \mathrm{2.5)} \mathrm{reaction:}$ The reaction color was yellowish or dark brown. 
9. PA-Red-ConA-HRP-AB ( $\mathrm{pH}$ 2.5) reaction: The terminal portion and excretory duct reacted negatively by this method. The reaction color of the glandular cells in the neck and body portions was from yellowish to dark brown.

10. PAD reaction: The reaction color of the glandular cells in the neck and upper body portions was brown, however, the lower body and terminal portions did not show any color.

11. Bowie's method for pepsinogen granules: A large number of pepsinogen granules were contained in all portions of the glands except the excretory duct (Figs. $25,26,27)$.

\section{The fundic glands}

The authors found some resemblance between the fundic glands and cardiac and esophageal cardiac glands during this study. Therefore, the observations on the cardiac and esophageal cardiac glands were also made on the fundic glands.

The authors believe that the gastric pit in the fundic gland corresponds to the excretory duct in the cardiac and esophageal cardiac glands, however, they conform to the description of the fundic glands.

The histochemical reactions of the fundic glands were as follows:

1. PAS stain: The gastric pits, mucous neck cells and the chief cells in the upper portion of the glandular body reacted strongly to PAS while the chief cells in the lower portion of the body and base of the glands reacted weakly or moderately to the same stain. Sometimes the reaction of the chief cells in the base was negative (Fig. 28).

2. $\mathrm{AB}(\mathrm{pH} 2.5)$ stain: Most of the glandular cells and the epithelium of the gastric pits reacted negatively to the same stain. However, the mucous neck cells and epithelium of the gastric pit rarely reacted weakly to $\mathrm{AB}$ ( $\mathrm{pH} 2.5$ ) (Figs. 29).

3. $\mathrm{AB}(\mathrm{pH} 0.5)$ stain: The glands generally reacted negatively to this stain while the mucous neck cells and epithelium of the gastric pit rarely reacted weakly to this technique.

4. PAS-AB ( $\mathrm{pH} 2.5)$ stain: The reaction color of the chief cells in the lower portion of the glandular body and base was light violet while the epithelium of the gastric pit, mucous neck cells and chief cells in the upper portion of the body in some glands was violet. The same cells in other glands reacted strongly to PAS.

5. LID (treated with $1 \% \mathrm{H}_{5} \mathrm{IO}_{6}$ ) reaction: The reaction color was light gray.

6. LID-AB ( $\mathrm{pH}$ 2.5) reaction: The epithelium of the gastric pits reacted very weakly to the $\mathrm{AB}(\mathrm{pH} 2.5)$ and some glandular cells reacted strongly to the same $\mathrm{AB}$. However, the glands reacted negatively to LID.

7. HID-AB ( $\mathrm{pH}$ 2.5) reaction: The epithelium of the gastric pits reacted very weakly to the $\mathrm{AB}(\mathrm{pH} 2.5)$ and the glandular cells reacted negatively to HID.

8. PA-ConA-HRP-AB ( $\mathrm{pH} 2.5$ ) reaction: The reaction color in the mucous neck cells was dark brown. The glandular cells in the upper body of the glands stained the same color, however, the reacted substance was small in quantity. The lower body and base of the glands reacted negatively to this technique. Sometimes, the same portions reacted positively to the same method. The epithelium of the gastric pits reacted very weakly to $\mathrm{AB}$ ( $\mathrm{pH} 2.5$ ).

9. PA-Red-ConA-HRP-AB (pH 2.5) reaction: The mucous neck cells and the immature chief cells in the upper portion of the glandular body reacted strongly to this technique. Namely, the reaction color was dark brown.

The immature chief cells in the lower portion of the glandular body and mature chief cells in the basal portion of the gland reacted negatively to this method. The epithelium of the gastric pits reacted very 
weakly or negatively to the $\mathrm{AB}$ ( $\mathrm{pH} 2.5$ ).

10. PAD reaction: The reaction color in the mucous neck cells and immature chief cells in the upper glandular portion was yellowish brown while the immature chief cells in the lower glandular portion and mature chief cells reacted negatively to this method. Incidentally, the same reaction color appeared in whole portions of several glands.

11. Bowie's methods for pepsinogen granules: Pepsinogen granules were found in the whole glandular cells (Figs. 30, 31). The same granules in the mucous neck cells were fine and those in the mature chief cells were coarse.

\section{Discussion}

The cardiac glands and upper and lower esophageal cardiac glands are generally considered to be the same kind of glands. Various opinions on the structure of the same glands are presented. Namely, Ichikawa et al. ${ }^{4)}$, Kelly et al. ${ }^{11)}$, OkajimaTaniguchi ${ }^{14)}$ believe that the esophageal cardiac glands are the branched tubular glands. Mori et al. ${ }^{13)}$ and Stöhr et al. ${ }^{18)}$ regard them as simple branched tubular glands. Junqueira-Carneiro ${ }^{9)}$ regards them as simple or branched tubular glands. The opinions of Bloom-Fawcett ${ }^{1)}$, Ito ${ }^{8)}$ and Tokari ${ }^{19)}$ are as compound tubular glands. The authors agree with this same view. Incidentally, the simple or simple branched tubular glands do not exist in the lamina propria mucosae of the esophagus.

There are only a few upper esophageal cardiac glands in the adult. Three out of seventeen specimens in this study contained the same glands in a small number and they were small in size. Ishizawa ${ }^{7)}$ describes the frequency of the above-mentioned glands in the fetus at about $90 \%$ or more but is lacking in 30 40\% of adults. Mori-Ogawa ${ }^{12)}$ and Stöhr et al. ${ }^{18)}$ say this rate is closer to $30 \%$. On the contrary, Ito $^{8)}$ describes the existence of these glands is $50 \%$ and the rate in Kaneko's ${ }^{10}$ ) description is $70 \%$. Based on the same percentages in the fetus and adult, the authors presume that the upper esophageal cardiac glands have a rudimentary tendency. Moreover, the same glands are smaller in size and number than those in the lower esophageal cardiac glands.

The authors cannot find a description on the frequency of lower esophageal cardiac glands. Incidentally, we recognized the same glands in all the specimens (15 individuals) used in this study. These glands surpass the upper esophageal cardiac glands in number and size. Namely, several large compound tubular glands are distributed in the terminal region of the esophagus.

The terminal portions of the compound tubular glands are tubules and they change into the smallest ducts. The same ducts drain into a large duct which is sometimes cystically dilated. The large duct changes into the excretory duct which passes through the esophageal stratified squamous epithelium and opens into the esophageal cavity. The simple columnar epithelium of the same duct is still simple in the esophageal epithelium. When the excretory duct of the esophageal gland passes through the esophageal epithelium, the simple cuboidal epithelium in the same duct changes into the stratified squamous epithelium. Moreover, the epithelium of the excretory ducts of the esophageal cardiac glands reacted strongly to PAS and $\mathrm{AB}(\mathrm{pH}$ 2.5). These characteristics are equal to the epithelium in the gastric pits. Incidentally, the epithelium of the excretory ducts in the esophageal glands reacted negatively to PAS and $\mathrm{AB}$ ( $\mathrm{pH} 2.5)$.

a) $A$ few parietal cells are scattered in the upper and lower esophageal cardiac glands. b) Bloom-Fawcett ${ }^{1}$, Ito $^{8)}$ and Tokari ${ }^{19)}$ describe the existence of the intercellular 
canaliculi in the glandular cells of the esophageal cardiac glands. c) The authors demonstrated pepsinogen granules in the cells of the terminal portions and ducts except the excretory duct of the abovementioned glands by Bowie's method for pepsinogen granules. d) The same glands contain neutral, weak and strong acid mucopolysaccharides, neutral mucus of types II and III and sialomucin.

The above-mentioned items a-d are very important in understanding the true character of the esophageal cardiac glands. The authors will discuss this subject later.

$\mathrm{Ham}^{3)}$, Ichikawa et $\mathrm{al}^{4)}$ and Ishizawa ${ }^{7)}$ believe that the cardiac glands are compound or simple tubular glands. JunqueiraCarneiro9)"s view is simple or branched tubular glands. Setoguchi ${ }^{17)}$ regards the cardiac glands as coiled simple branched tubular glands and these are same kind as the lower esophageal cardiac glands. According to Ross-Reith ${ }^{16)}$, the cardiac glands are tubular and coiled. Ito $^{8)}$ and Tokari ${ }^{19)}$ regard the cardiac glands as compound tubular glands. However, the so-called cardiac glands are not simple but are composed of several compound tubular glands and a large number of simple or simple branched tubular glands. The compound tubular glands are generally distributed in the region neighboring the ostium cardiacum and contact the lower esophageal cardiac glands. Simple or simple branched tubular glands occupy the spaces lacking the compound tubular glands. Occasionally, several simple or simple branched tubular glands are adjacent to the ostium cardiacum. In these cases, there is no doubt that the compound tubular glands are distributed apart from the same ostium. The same glands in the cardiac region are unrecognizable in some materials. The compound tubular glands are similar in structure to the esophageal cardiac glands and the simple or simple branched tubular glands are similar to the fundic glands. However, the formers are shorter but larger than the fundic glands. The authors decided that the base, body and excretory ducts exist in the simple or simple branched tubular gland. The excretory duct corresponds to the gastric pit of the fundic gland and the body and base are equal to the duct and terminal portion of the compound tubular gland.

Ishizawa $^{7)}, \quad$ Ito $^{8)}, \quad$ Setouchi $^{17)}$ and Tokari $^{19)}$ describe the existence of parietal cells in the cardiac glands. The authors also recognized the same cells in the compound tubular and simple or simple branched tubular glands in the cardiac region.

According to Ichikawa et al. ${ }^{4)}$ and Ito $^{8)}$ a few argentaffine cells are found in the cardiac glands. Bargmann ${ }^{2)}$ and MoriOgawa ${ }^{12)}$ describe the existence of intercellular canaliculi between chief cells neighboring each other. The authors did not investigate the above-mentioned subjects.

$\mathrm{Ham}^{3)}$ presume the secretion of some enzyme in the cardiac glands and JungueiraCarneiro ${ }^{9)}$ believed that the same glands probably secreted the enzyme lysozyme.

The authors demonstrated pepsinogen granules in the compound and simple or simple branched tubular glands in the cardiac region by Bowie's method for pepsinogen granules. The same granules are recognizable in the terminal portions and ducts except the excretory duct in the compound tubular glands and the base, body and neck portions of the simple or simple branched tubular glands.

Some investigators $1,3,4,9,11,13-17,20,21$ ) believed that the cardiac glands and esophageal cardiac glands secreted mucous. According to Bargmann ${ }^{2)}$, Ishizawa ${ }^{7)}$, Ito $^{8)}$ and Tokari ${ }^{19)}$ the above-mentioned glands secret mucoid.

The authors demonstrated neutral, weak and strong acid mucopolysaccharides, neutral mucus of types II and III and sialomucin in the esophageal cardiac glands, 
compound tubular glands and simple tubular or simple branched tubular glands in the cardiac region.

The fundic (gustric) glands also possess the above-mentioned substances, pepsinogen granules and parietal cells, argentaffine cells and intercellular canaliculi. Therefore, the authors believed that the so-called cardiac glands, and esophageal cardiac glands are the same kind as the fundic glands. Namely, the terminal portions of the compound tubular glands in the cardiac region, upper lower esophageal cardiac glands correspond to the basal portions in the fundic glands and the body and neck portions in the same glands are equal to the ducts in the compound tubular glands.

Why are the compound type of the fundic glands made in the esophagus? The authors presume that the compound type is more advantageous than the scattering simple tubular glands to the mechanical injury of the glands which is caused by passing foods. For example, the fundic glands of the pangolin lie under the stratified squamous epithelium in a mass and open into the gastric cavity with one excretory duct (Fig. A). The pyloric and body glands (tentative name) gather in a number of

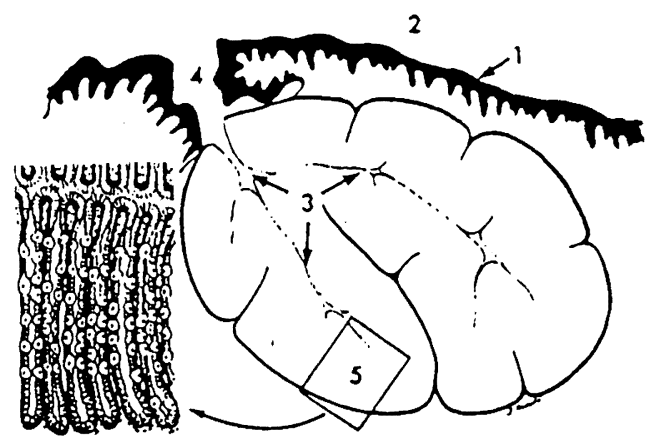

Fig. A. Cross section of the glandular mass consisting of fundic glands (scheme). 1: stratified squamous epithelium. 2: cavity of the stomach. 3: lumen which the pits open into. 4: duct of the fundic glands. 5: fundic glands. (After Imai-Shibata-Mineda) masses (Figs. B \& C). ${ }^{5)}$ Incidentally, animals directly take living ants, fragments of their nest, sand and the like into the stomach because they have no teeth. To compensate for this, the epithelium of the gastric mucous membrane is thick and strongly cornified stratified squamous epithelium. Taking this into consideration, the esophageal cardiac glands in man and glands in the stomach of the pangolin have many

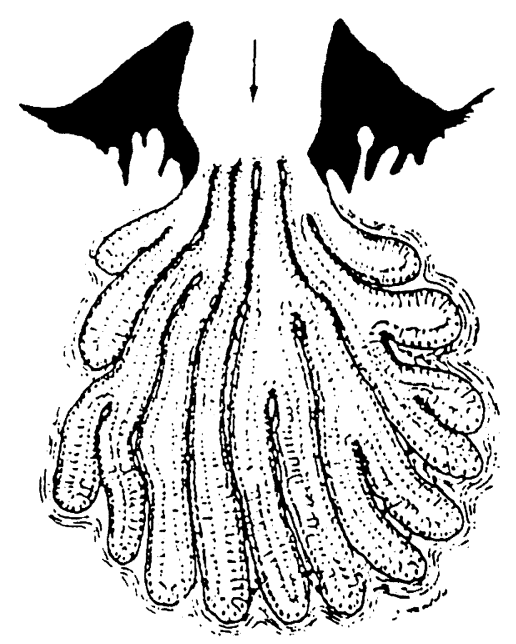

Fig. B. Scheme of the mass consisting of the pyloric glands. $\downarrow$ : Excretory duct of the glands. (After Imai-Shibata-Mineda)

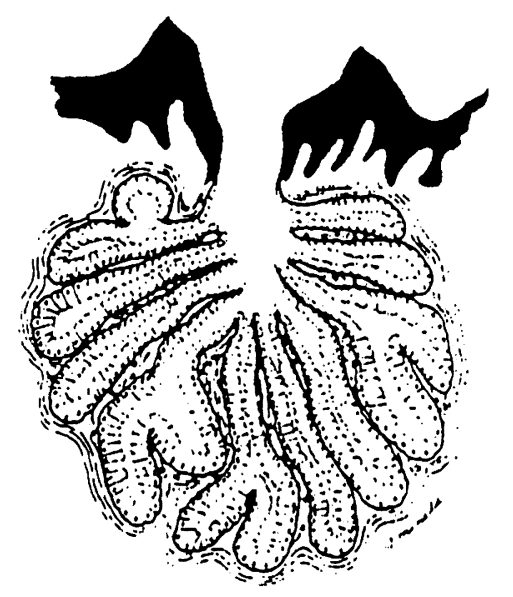

Fig. C. Scheme of the mass consisting of the body glands. (After Imai-Shibata-Mineda) 
points of similarity in the structure.

The authors believe the so-called cardiac glands which are composed of compound tubular glands and simple or simple branched tubular glands are undifferentiated fundic glands because they generally reacted strongly to PAS with the exception that some terminal portions partially reacted weakly or negatively. The mucous neck cell and immature chief cells in the fundic glands contain a PAS positive substance, however, the mature chief cells reacted weakly or negatively to $\mathrm{PAS}^{6}$ ).

The authors believe that the increase or decrease of the PAS positive substance in the fundic glands is an indication of undifferentiation or differentiation.

Ishizawa ${ }^{7)}$ describes the presence of the cardiac glands in man as unnatural and he presumes the same glands are imcomplete fundic glands. Moreover, he maintains that the lower esophageal cardiac glands are unusual ectopia of a piece of the gastric mucous membrane in the esophagus. OgawaHosokawa $^{13)}$ states that the upper and lower esophageal cardiac glands may be regarded as the ectopia of a part of the cardiac glands in the esophagus.

However, since there are about 90\% upper esophageal cardiac glands in the fetus, the above-mentioned opinions are unacceptable. The authors presume that the same glands are normal structures in the esophagus and develop from the cranial side to the caudal side. Therefore, the so-called cardiac glands (compound tubular type) are deemed extended portions of the lower esophageal cardiac glands in the cardiac region. Incidentally, several esophageal glands are occasionally also found in the same region (Fig. 32).

Accordingly, the authors propose the terms of upper and lower esophageal fundic glands instead of the upper and lower esophageal cardiac glands and the simple or simple tubular glands in the cardiac region are regarded as undifferentiated fundic glands. The cardiac glands which are considered by other scholars do not exist in man.

We have data on the histlogical structure of the lower end of the esophagus and cardiac region in the Japanese macaque, crab-eating monkey, dog, cat, rabbit, cow, horse, swine, rat and mouse, however, they did not find the gland which corresponds to the esophageal cardiac gland or compound tubular gland in the cardiac region. The existence of the esophageal cardiac glands and compound tubular glands in the cardiac region is a characteristic in man.

Bloom-Fawcett ${ }^{1)}$ describe the island of the gastric mucousa in the esophagus, however, the materials used in this study did not contain such an abnormal structure.

\section{References}

1) Bloom, W. \& Fawcett, D.W.: A Textbook Histology, 9th ED., 544-545, 554. W.B. Saunders Co., Philadelphia-London-Toronto, 1970.

2) Bargmann, W.: Histologie und mikroskop. Anat. d. Menschen. 6. überarbeit. Aufl., 426,429,431. Georg Thieme Verlag, Stuttgart, 1967.

3) Ham, A.W.: Histology, 6th ED., 683,686. J.B. Lippincott Co., Philadelphia-Toronto, Igaku Shoin Ltd., Tokyo, 1st Printing (Asian Ed.) 1969.

4) Ichikawa, A., Omochi, S., Shibasaki, S., Setoguchi, T., Nagata, T., Hatai, B. and Yamada, K.: Newest Histology, 6th Ed. 265, 267. Nankodo, Tokyo-Kyoto, 1977 (in Japanese).

5) Imai, M., Shibata, T., Mineda, T., Suga, Y. and Onouchi, T.: Histological and histochemical investigations on the stomach in man and some other kinds of animals. Report V. On the stomach of the pangolin (Manis pentaductyla Linne). Okajimas Folia Anat. Jpn., 49: 433-454, 1973.

6) Imai, M., Shibata, T. and Mineda, T.: Histological and histochemical investigations on the stomach in man, Japanese monkey (Macaca fuscata yakui) and some other kinds of animals. Report III. The so-called im- 
mature chief cell. Okajimas Folia Anat. Jpn. 43: 119-131, 1967.

7) Ishizawa, M.: Manual of Histology, Vol. 2, 228-230, 246. Nihon Isho Press, TokyoKyoto, 1951 (in Japanese).

8) Ito, T.: Histology, 17th Ed., 302, 308. Nanzando Co. Tokyo, 1977 (in Japanese).

9) Junqueira, L.G. \& Carneiro, J.: Basic Histology. 4th Ed. 320-321. Large Medical Publications. Maruzen Asia, 1983.

10) Kaneko, U.: Japanese Human Anatomy, Vol. II, 8th Ed., 55. Nanzando Co., Tokyo, 1964 (in Japanese).

11) Kelly, D.E., Wood, R.L. and Enders, A.C.: Bailey's Textbook of mikroscop. Anat. 18th Ed., 530-532, 535, 540-542. Williams \& Wilkins, Baltimore/London, 1971.

12) Mori, O. \& Ogawa, T.: Small Histology. Vol. II, 9th Ed. 150-151, 153. Nihon Isho. Publ. Co., Tokyo, Kyoto, 1951 (in Japanese).

13) Mori, O., Hirasawa, K., Ogawa, T., Mori, Y., Okamoto, M., Ouchi, H., Mori, T., Hosokawa, H. and Yamamoto, T.: Anatomy. Vol. III (Ogawa T. \& Hosokawa, H.), 10th Ed. 126, 132-135. Kanahara Publ. Co., Tokyo, Osaka, Kyoto, 1976 (in Japanese).

14) Okajima, K. \& Taniguchi, T.: Okajima Anato- mie. Bd. III, 53, 61. Kanahara Publ. Co., Kyorin Shoin, 1964 (in Japanese and German).

15) Osogoe, B. \& Awaya, K.: Fundamental Anatomy. 151. Asakura Shoten, Tokyo, 1980 (in Japanese).

16) Ross, M. \& Reith, E.J.: Histology. 416, 423. Harper \& Row, Publishers, J.B. Lippincott Company, New York, Cambridge, Philadelphia, San Francisco, London, Mexico City, Sao Paulo, Singapore, Sydney, 1985.

17) Setoguchi, T.: Textbook of Practical Histology, 142, 145. Nanzando Co., Tokyo, 1979 (in Japanese).

18) Stöhr, P., v. Möllendorff, W. and Goerttler, K.: Lehrbuch der Histologie und der mikroskop. Anat. d. Menschen. 374-376, 380-381. Gustav Fischer, Stuttgart, 1969.

19) Tokari, C.: Histology. 5th Ed. 249-250, 254. Nanzando, Tokyo, 1960 (in Japanese).

20) Weiss, L. \& Greep, R.O.: Histology, 4th Ed., 666, 668-669. Mcgraw-Hill Book Company, New York et al., 1977.

21) Wheater, P.R., Bunkitt, H.G., Daniels, V.G. and Deakin, P.J.: Functional Histology, 184. Churchill Livingstone, Edinburgh London and New York, 1979. 


\section{Explanation of Figures}

\section{Plate I}

Fig. 1. 1: Upper esophageal cardiac gland.

2: Esophageal gland.

$\mathrm{AB}(\mathrm{pH} 0.5)$ stain. $\times 200$.

Fig. 2. $\uparrow$ : Parietal cells in the upper esophageal cardiac gland. PAS stain. $\times 400$.

Fig. 3. Epithelium in the excretory duct of the esophageal gland. PAS stain. $\times 100$.
A: Columnar epithelium in the duct.
B: Stratified squamous epithelium in the duct.
C: Esophageal stratified squamous epithelium.

Fig. 4. Pepsinogen granules in the upper esophageal cardiac gland. Bowie's method for pepsinogen granules. $\times 600$.

Fig. 5. Lower esophageal cardiac glands. PAS stain. $\times 40$.
A: Excretory duct.

Fig. 6. Lower esophageal cardiac glands. $\mathrm{AB}(\mathrm{pH} 2.5)$ stain. $\times 40$.
A: Excretory duct.
B: Lymphatic nodule.

Fig. 7, 8. arietal cells $(\uparrow)$ in the lower esophageal cardiac gland. PAS stain. $\times 400$. 


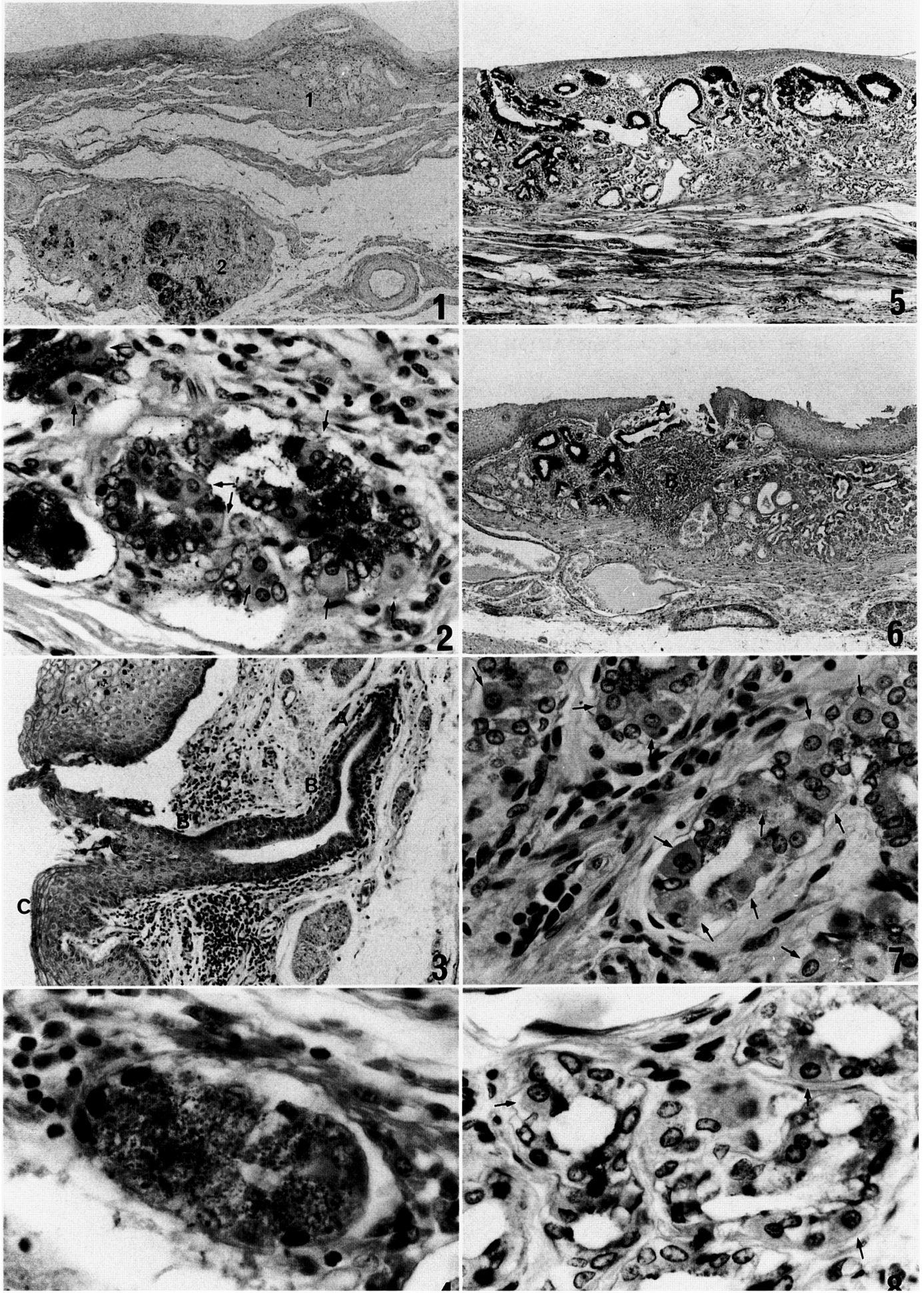




\section{Plate II}

Fig. 9. Lower esophageal cardiac gland. $\mathrm{AB}(\mathrm{pH} 0.5)$ stain. $\times 100$.

Fig. 10. Pepsinogen granules in the lower esophageal cardiac gland (A). Bowie's method for pepsinogen granules. $\times 600$.

Fig. 11. Pepsinogen granules in the lower esophageal cardiac gland (A, B, C). Bowie's method for pepsinogen granules. $\times 600$.

Fig. 12. Pepsinogen granules in the lower esophageal cardiac gland (A, B). Bowie's method for pepsinogen granules. $\times 600$.

Fig. 13. Pepsinogen granules in the lower esophageal cardiac gland (A, B, C). Bowie's method for pepsinogen granules. $\times 400$.

Fig. 14. Lower esophageal gland (A) and compound tubular gland in the cardiac region (B). PAS stain. $x$ 20.

$\uparrow:$ Esophagogastric junction.

Fig. 15. Lower esophageal glands (A-C) compound tubular glands (D, E) and simple branched tubular glands $(F, G)$. PAS stain. $\times 30$.

$\uparrow$ : Esophagogastric junction.

Fig. 16. Simple or simple branched tubular glands (A, B) and compound tubular glands $(C)$ in the cardiac region neighboring Fig. 15. PAS stain. $\times 40$. 
Plate II
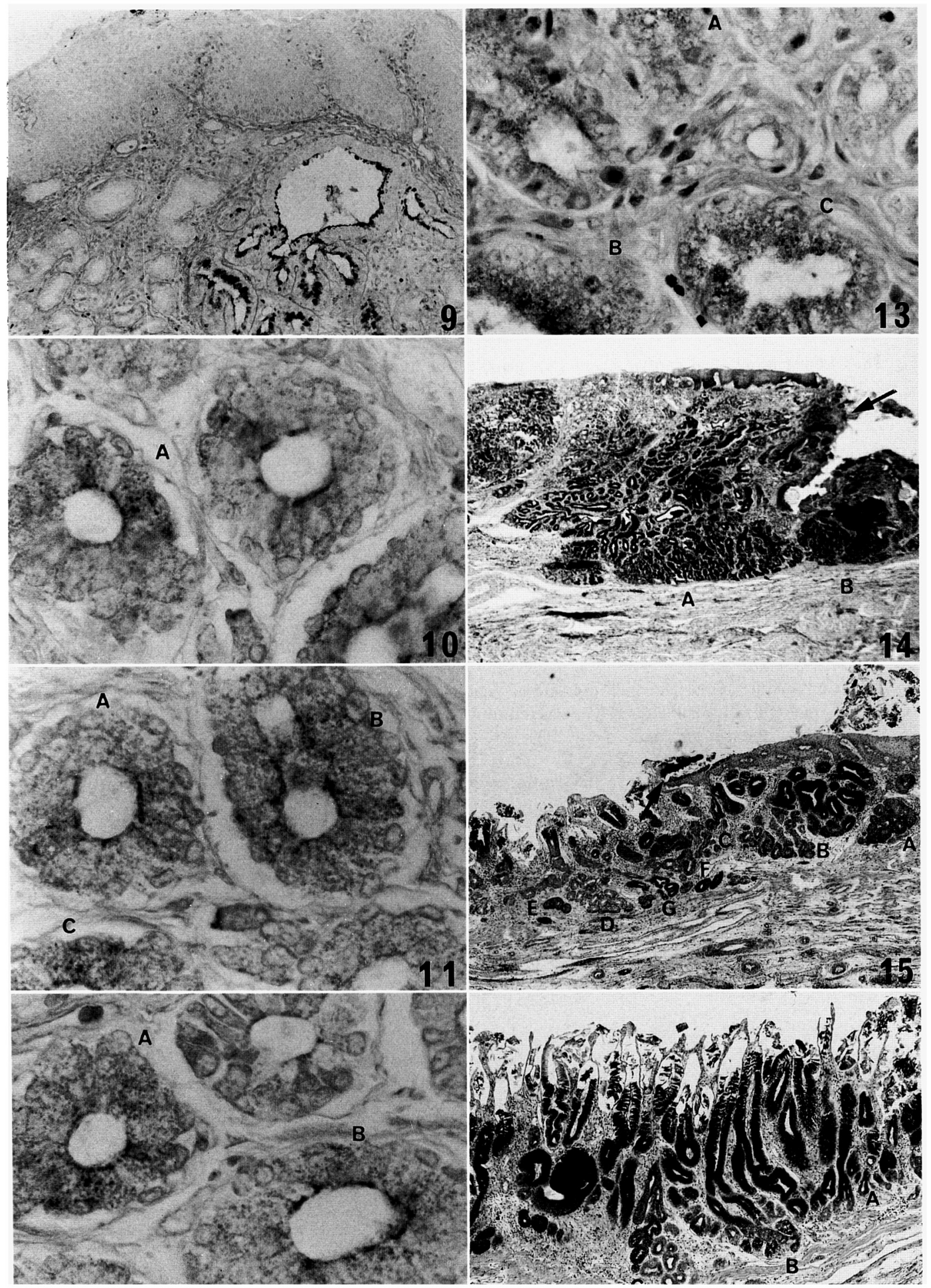


\section{Plate III}

Fig. 17. Simple or simple branched tubular glands (A-C) and compound tubular gland (D-F) in the cardiac region neighboring Fig. 16. PAS stain. $\times 30$.

Fig. 18. Lower esophageal cardiac gland (A), gland in the esophagocardiac junction (B) and compound tubular gland in the cardiac region (C). PAS stain. $\times 40$.

$\uparrow$ : Esophagogastric junction.

Fig. 19. Compound tubular glands (A-E) and simple or simple branched tubular glands (F-G) in the cardiac region neighboring the orificium cardiacum. PAS stain. $\times 30$.

Fig. 20. Excretory ducts and some ducts of the compound tubular glands in the cardiac region reacted to $\mathrm{AB}(\mathrm{pH} 2.5)$. Their terminal portions are negative to the same AB. $\times 40$.

A: Lower esophageal cardiac gland.

$\uparrow:$ Esophageal epithelium.

Fig. 21. Parietal cells $(\uparrow)$ in the compound tubular glands in the cardiac region. PAS stain. $\times 400$.

Fig. 22. Compound tubular glands in the cardiac region. Epithelium in the excretory duct (A), expanded large duct (B) and small ducts (C, D) reacted to $\mathrm{AB}(\mathrm{pH} 2.5) \times 40$.

$\uparrow:$ Esophagogastric junction.

Fig. 23. Compound tubular glands in the cardiac region. Most of them reacted negatively to $\mathrm{AB}(\mathrm{pH} 0.5)$ except (A). $\times 40$.

$\uparrow$ : Esophagogastric junction.

Fig. 24. Pepsinogen granules in the compound tubular gland in the cardiac region. Bowie's method for pepsinogen granules. $\times 600$. 
Plate III

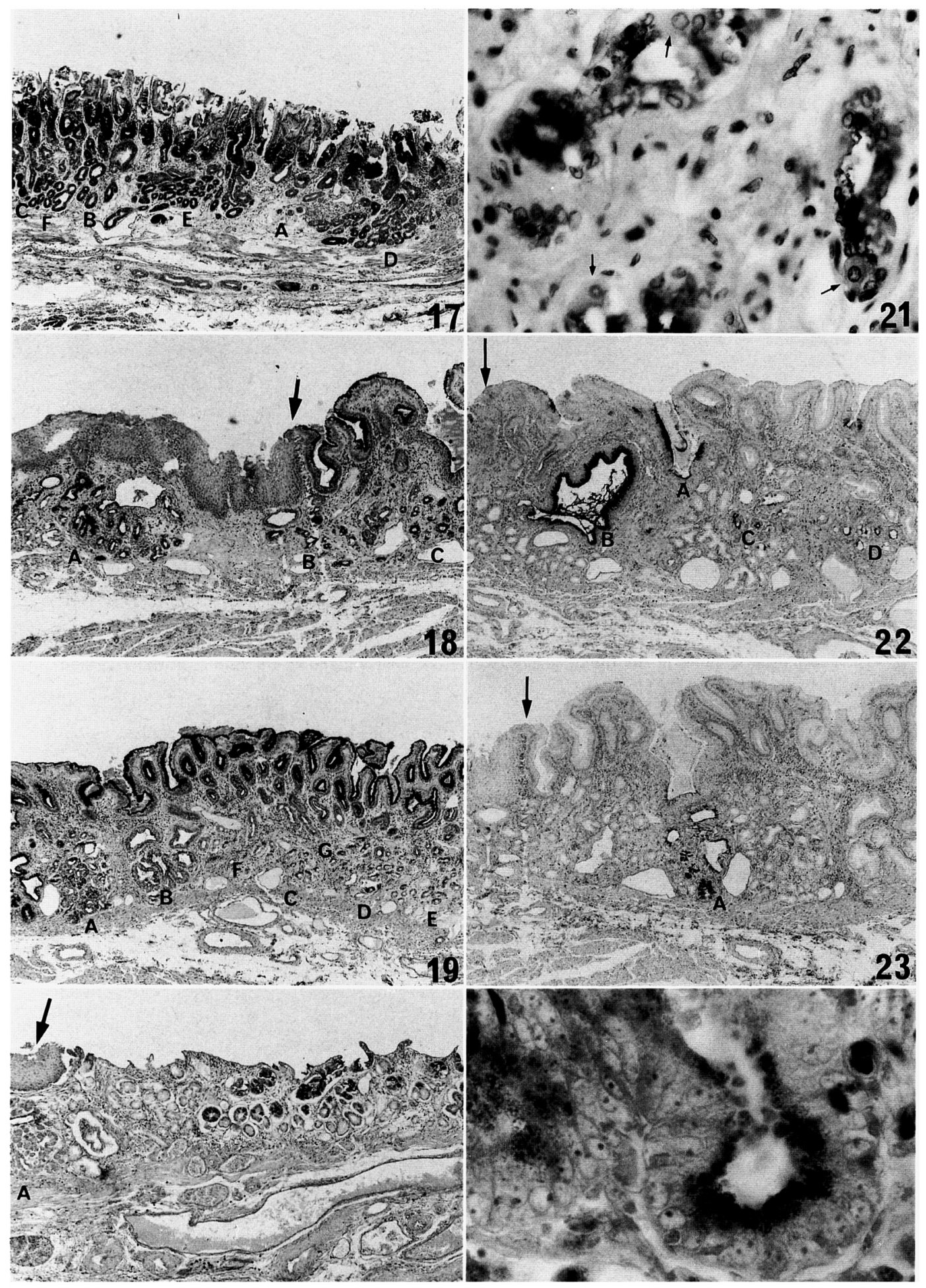




\section{Plate IV}

Fig. 25-27. Pepsinogen granules in the simple branched tubular glands in the cardiac region. Bowie's method for pepsinogen granules. Figs. 25, 27: x 600, Fig. 26: × 750.

Fig. 28. Fundic glands reacted weakly or negatively to PAS. $\times 75$.

Fig. 29. Fundic glands. The epithelium of the gastric pits reacted weakly to $A B(\mathrm{pH} 2.5)$ while the glands were negative to the same AB. $\times 100$.

Fig. 30. Pepsinogen granules in the fundic glands (dark portions). Bowie's method for pepsinogen granules. x 100 .

Fig. 31. Pepsinogen granules in the fundic glands. Numerous coarse granules are visible. Bowie's method for pepsinogen granules. $\times 600$.

Fig. 32. Esophageal glands and compound tubular gland (the so-called cardiac gland) in the cardiac region.

$\mathrm{AB}(\mathrm{pH} 0.5)$ stain. $\times 15$.

A-E: Esophageal glands.

F: The so-called cardiac gland.

G: Esophageal epithelium. 


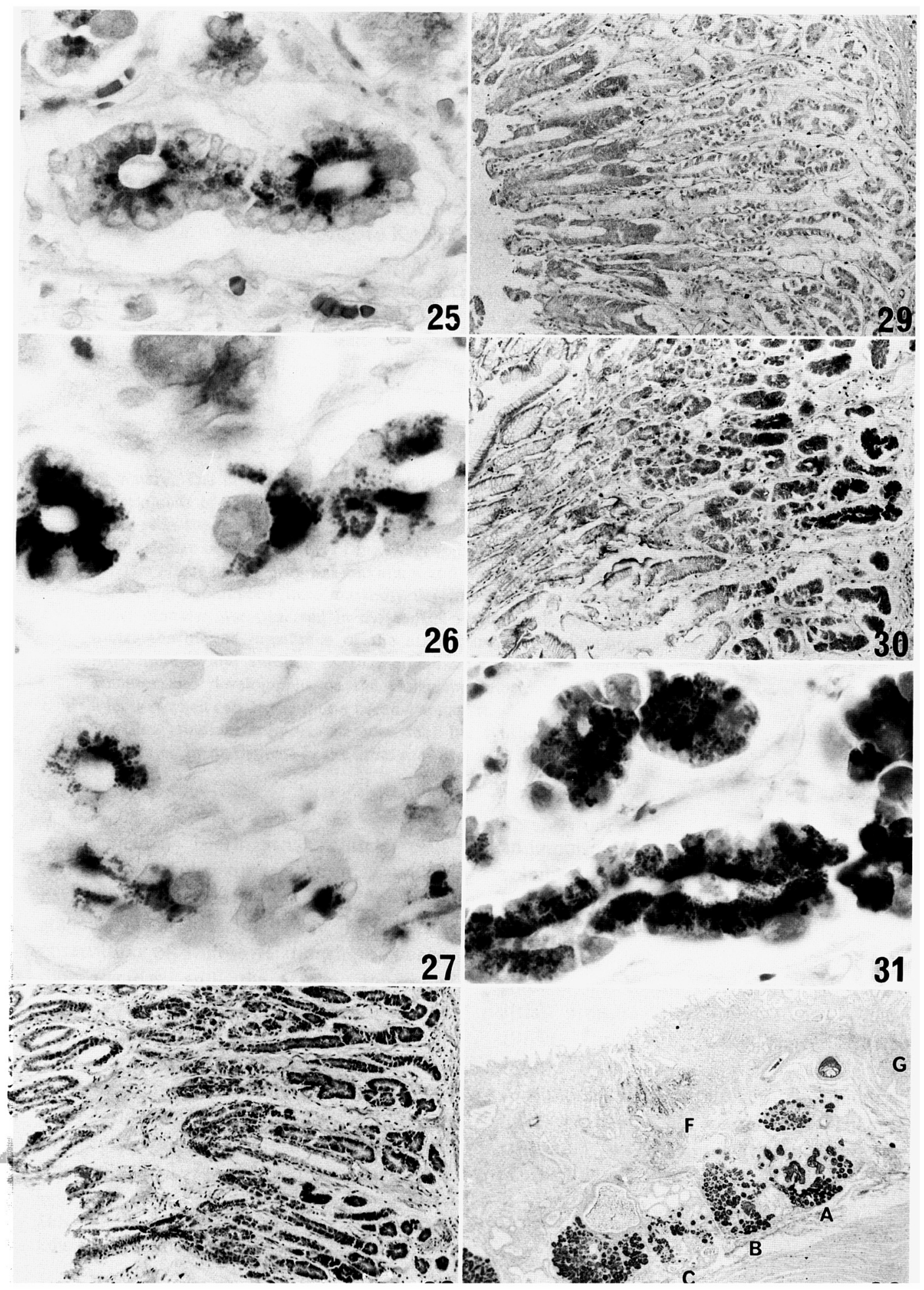

